\title{
GLACIER SLIDING DOWN AN INGLINED WAVY BED WITH FRICTION
}

\author{
By L. W. MORLAND
}

(School of Mathematics and Physics, University of East Anglia, Norwich NR 47 TJ, England)

Abstract. The effects of frictional tangential traction combined with regelation on the basal sliding of a temperate glacier down an inclined wavy bed are examined. Two friction models are treated. First, a Coulomb law model having the assumptions that sliding occurs everywhere and that the tangential traction is proportional to the normal pressure. Secondly, a velocity power law in which the tangential traction is proportional to a power of the slip velocity. The ice motion is approximated by steady slow Newtonian flow and the bed undulation about a mean bed-line has a maximum slope $\epsilon \ll 1$. Flow solutions are constructed as perturbations (in powers of $\epsilon$ ) of the plane laminar flow corresponding to non-slip on the mean bed-line, assuming that the ice remains everywhere in contact with the bed; that is, no cavitation takes place. If the normal traction is predicted to be tensile over part of the bed, implying that cavitation has occurred, then a new solution is needed in which the ice base over cavities is traction-free. Since the cavity sections and profile of the free ice base are then part of the overall solution, an intricate mixed boundary-value problem is set up for the flow and the present analysis is inadequate.

For a sinusoidal bed the perfect-slip (zero tangential traction) solution predicts compressive normal traction everywhere on the bed provided that the mean bed-line inclination $\alpha$ (to the horizontal) is less than a critical value $\alpha_{\mathrm{c}}$ which is of order $\epsilon$. For greater values of $\alpha$, including a range of order $\epsilon$, the normal traction is tensile on some parts of the bed, and a solution with cavitation is needed. If the tensile sections are relatively small it is expected that the resulting cavitation will not change the overall solution significantly. However, the Coulomb friction solution has extensive zones of tensile traction for all values of $\alpha$, so that extensive cavitation would occur. In contrast, the velocity-power friction solution has compressive traction everywhere on the bed for $\alpha \leqslant \alpha_{c}=O(1)$ provided that the ice depth is not too large, and also for deep glaciers for $\alpha \leqslant \alpha_{c}=O(\epsilon)$. Furthermore, the predicted basal sliding velocity varies much less with the length scale of the bed undulation than in the perfect-slip solution, and is smaller.

RÉsumé. Glissement d'un glacier avec frottement sur un lit incliné ondulé. On a examiné les effets de la traction tangentielle de frottement combinée avec le regel sur le lit d'un glacier tempéré glissant sur un fond incliné avec des ondulations. Deux modèles de frottement sont envisagés: le premier est une loi de Coulomb dans laquelle la traction tangentielle est proportionnelle à la pression normale, le second est une loi-puissance en fonction de la vitesse dans laquelle la traction tangentielle est proportionnelle à une puissance de la vitesse de glissement. Le mouvement de la glace est assimilé à un écoulement státionnaire lent Newtonien et les ondulations du lit autour d'une direction moyenne, ont une pente maximum $\epsilon \ll 1$. Les solutions pour l'écoulement sont construites comme des perturbations en puissances de $\epsilon$ autour de l'écoulement plan laminaire correspondant au non-glissement sur le lit plan moyen, avec l'hypothèse que la glace reste partout au contact du lit, c'est-à-dire qu'il n'y a pas cavitation. Si l'on prévoit que l'effort normal sur une partie du lit sera une traction, ce qui implique que la cavitation peut se produire, alors il faut une nouvelle solution dans laquelle la glace de la base au-dessus des cavités n'est pas soumise à une traction. Dès lors que les profil et sections des cavités de la glace libre de la base font partie de la solution générale, un problème inextricable de valeurs aux limites est soulevé par la détermination de l'écoulement et la présente analyse est inadéquate.

Pour un lit sinusoïdal, la solution du glissement parfait (traction tangentielle nulle) prévoit un effort normal de compression partout sur le lit pourvu que la pente moyenne $\alpha$ (sur l'horizontale) soit inférieure à une valeur critique $\alpha_{c}$ qui est de l'ordre de $\epsilon$. Pour des valeurs supérieures de $\alpha$, y compris un ordre de grandeur voisin de $\epsilon$, il y a un effort de traction normal quelque part sur le lit, et il est nécessaire de chercher une solution avec cavitation. Si les sections avec traction sont relativement petites, on s'attend à ce que la cavitation résultante ne change pas la solution générale de manière significative. Cependant, la solution de la friction de Coulomb présente de larges zones avec efforts normaux de traction pour toutes les valeurs de $\alpha$, si bien qu'une cavitation importante peut s'y produire. Par contre, la solution avec frottement en puissance de la vitesse est valable partout si $\alpha \leqslant \alpha_{c}$ avec une valeur $\alpha_{c}=O(1)$, pourvu que la profondeur du glacier ne soit pas excessive, et aussi pour les glaciers profonds lorsque $\alpha \leqslant \alpha_{\mathrm{c}}$ avec $\alpha_{\mathrm{c}}=O(\epsilon)$. En conséquence, la vitesse de glissement à la base qui est prédite, varie beaucoup moins avec l'échelle des longueurs d'onde des irrégularités du lit que dans la solution à glissement parfait et est plus faible.

Zusammenfassung. Gletschergleiten über ein geneigtes und gewelltes Bett mit Reibung. Untersucht wird die Auswirkung tangentialen Reibungszuges in Kombination mit Regelation auf das Gleiten eines temperierten Gletschers über ein geneigtes und gewelltes Bett. Zwei Reibungsmodelle werden herangezogen: erstens ein Coulomb-Gesetz, bei dem die tangentiale Reibung proportional zum Normaldruck anwächst; zweitens ein Geschwindigkeitspotenzgesetz, bei dem die tangentiale Reibung proportional zu einer Potenz der Gleitgeschwindigkeit ist. Die Eisbewegung wird durch stationäres, langsames Newtonsches Fliessen angenähert; die Bettundulation um ein mittleres Bettprofil hat eine Maximalneigung von $\epsilon \ll \mathrm{I}$. Die Lösungen für das Strömungsfeld werden als Störungen der ebenen laminaren Strömung, bei der kein Gleiten auf dem mittleren Bettprofil stattfindet, nach Potenzen von $\epsilon$ entwickelt; dabei wird angenommen, dass das Eis überall mit dem Bett in Berührung bleibt, d.h. keine Kavitation stattfindet. Für den Fall, dass sich eine Normalkomponente der Kraft über einem Teil des Bettes in Zugrichtung ergibt, braucht man eine neue Lösung, die Kavitation 
einschliesst, und bei der die Eisuntergrenze über den Hohlräumen reibungsfrei ist. Da die Hohlraumabschnitte und das Profil der freien Eisuntergrenze dann einen Teil der Gesamtlösung bilden, erhält man für das Fliessen ein verwickeltes vermischtes Randwertproblem und die vorliegende Untersuchung ist unzulänglich.

Für ein sinusförmiges Bettprofil liefert die Lösung für vollkommenes Gleiten (ohne tangentiale Reibung) überall im Bett eine Normalkraft in Druckrichtung, vorausgesetzt, die Neigung $\alpha$ des mittleren Bettprofils gegenüber der Waagrechten ist kleiner als ein kritischer Wert $\alpha_{\mathrm{e}}$ (in der Grösse von $\epsilon$ ). Fur höhere Werte von $\alpha$, einschliesslich eines Bereiches in der Grösse von $\epsilon$, ist die Normalkraft an einigen Stellen des Bettes in Zugrichtung, und man braucht eine Lösung mit Kavitation. Wenn die Abschnitte unter Zug verhaltnismässig klein sind, wird angenommen, dass die entstehende Kavitation die Gesamtlösung nicht entscheidend verändert. Die Lösung für die Coulomb-Reibung hat jedoch für alle Werte von $\alpha$ ausgedehnte Zonen unter Zug, so dass entspechende ausgedehnte Kavitation auftreten wird. In Gegensatz dazu gilt die Lösung mit Reibung nach dem Geschwindigkeitspotenzgesetz überall, wenn $\alpha \leqslant \alpha_{c}=O(1)$, vorausgesetzt, dass die Eisdicke nicht zu gross ist, und auch für mächtige Gletscher, wenn $\alpha \leqslant \alpha_{\mathrm{c}}=O(\epsilon)$. Des weiteren schwankt die vorausgesagte Gleitgeschwindigkeit weit weniger mit der Längenausdehnung der Bettundulation als in der Lösung des vollkommenen Gleitens und ist niedriger.

\section{INTRODUCTION}

A thin water layer produced by the melting and refreezing of basal ice in a temperate glacier on up- and down-stream faces of bed protuberances provides lubrication for the basal sliding which may be a significant part of the overall motion. The shear stress in such a thin layer is negligible and so there is no resistive tangential traction to the ice motion over the bed. The bed drag is the resultant, along the mean bed line, of the pressure distribution over the protuberances. This perfect-slip model is the basis of flow solutions obtained by Nye (1969, 1970), Kamb (1970), and more recently, Morland (1976). It is assumed that the ice can be approximated as an incompressible Newtonian fluid of high viscosity in slow steady flow, and that the bed profile is periodic with small maximum slope $\epsilon$ relative to the bed line. Solutions are obtained as power series expansions in $\epsilon$, assuming that the ice base remains everywhere in contact with the bed. For a given glacier depth $h$, an inclination $\alpha$ of the mean bed line to the horizontal, and a profile shape, the plane flow solution determines the basal-sliding velocity, which is defined as the tangential velocity along the mean bed line. A calculation for a sinusoidal bed shows that the basal-sliding velocity is sensitive to the length scale of the bed undulation. Furthermore, the normal traction on the bed remains compressive everywhere only if $\alpha \leqslant \alpha_{c}$ for some critical angle $\alpha_{c}$ which is of order $\epsilon$, and hence the solution predicts tensile tractions on part of the bed for $\alpha$ of the order of one and for some range of $\alpha$ of order $\epsilon$. In these situations cavitation must occur, and a valid formulation must incorporate cavity sections over which the ice base is traction free, these sections and the profile of the ice base being part of the solution. This intricate problem involving, as it does, such mixed boundary values, has not yet been attempted. It is, however, expected that when the tensile sections are relatively small, the resulting cavitation will not have a significant effect on the overall solution.

The condition of zero tangential traction requires the existence of a continuous water layer. Pinching-out of the water layer at the crests of protuberances will cause local failure of this condition, but debris protruding from the basal ice makes frictional contact with the bed across the large areas over which it is carried (Boulton, 1974, p. 41; 1975, p. 7). The interaction of such debris with the bed is complex, as is its dependence on bed profile (which reveals how it is transported and deposited). Data obtained by G. S. Boulton, A. Armstrong and E. M. Morris from field work carried out on the Glacier d'Argentière in 1973 and 1975 are being analysed in an attempt to construct "simple" friction laws exhibiting the main features observed in different situations. To ensure a manageable analysis one must assume that the mean effect of the individual debris contacts can be described by friction laws which apply continuously over the bed surface. It is with such an analysis in mind that any possible qualitative effects of bed friction on basal sliding are explored here, by solving the plane flow problem for two conventional friction laws. 
First, the Coulomb law

$$
t_{s}=-v t_{n}
$$

where $t_{s}$ and $t_{n}$ are the tangential. and normal tractions on the ice base, with $s$ defining a tangential coordinate in the direction of flow and $n$ a normal coordinate directed into the ice, $\nu$ is the friction coefficient assumed to be of order unity. The limiting friction form of Equation (I) presupposes that sliding occurs everywhere. It is reasonable to assume that any non-slip zones will be of limited extent and should not influence significantly the overall basal sliding.

Secondly, a velocity power law

$$
t_{s}=E V_{s^{1 / m}},
$$

where $V_{s}$ is the tangential velocity of the base ice, and $E$ and $m$ are constants. The form of Equation (2) has been used by Nye (1959) in a different context, and is also inferred by Weertman (1957, 1964) as a global relation between mean drag and basal-sliding velocity in his regelation theory which takes a non-linear viscous law for the ice. Weertman suggested that $m$ is approximately 2 or a little larger, but gave no explicit value for $E$. In the present analysis, however, Equation (2) is considered as a possible qualitative relation arising from debris friction, in contrast with Equation ( 1 ), and also in an exploration of its effects on basalsliding velocity and cavitation. A value of $m=2$ is used in the calculations, and a range of values for $E$ compatible with steady flow down the inclined bed is considered.

If part of the work done by the basal friction is released as a surface heat flux, and not used solely for surface crushing or other mechanical effects, it contributes to the thermal balance in the regelation mechanism and a non-linear thermo-mechanical coupling is introduced into the boundary conditions. When only a small part is released as heat this coupling may be neglected, and it is also shown here that, under moderate restrictions on the glacier depth and bed profile slope, the entire work contribution is small compared with the latent-heat terms. The solutions are therefore derived neglecting any friction contribution to the thermal balance, so that the surface distribution of heat sources at the ice base per unit area, is $L V_{n}$ (Nye, 1969), where $\dot{L}=2.8 \times 10^{8} \mathrm{~J} \mathrm{~m}^{-3}$ is the latent heat and $V_{n}$ is the normal velocity of the basal ice. Thus, at the bed

$$
-k_{\mathrm{i}} \frac{\partial T}{\partial n}+k_{\mathrm{b}} \frac{i S}{\partial n}=L V_{n}
$$

where $T$ and $S$ denote temperature in the ice and bedrock respectively, and $k_{\mathrm{i}}$ and $k_{\mathrm{b}}$ are the thermal conductivities of ice and bedrock respectively. $k_{\mathrm{i}}=2.1 \mathrm{~J} \mathrm{~m}^{-1} \mathrm{~s}^{-1} \mathrm{~K}^{-1}$ and $k_{\mathrm{b}}=r k_{\mathrm{i}}$ where $r$ ranges from 1 to 2 for typical bed rocks; the value $r=1.6$ (appropriate to granite) is used in later calculations. In the regelation model the basal ice is everywhere at its melting point, and if $\left(p_{0}, T_{0}\right)$ is a pressure-melting point on the bed-line, then at the bed

$$
T-T_{0}=S-T_{0}=-C\left(p-p_{0}\right) .
$$

Such a linear relation presupposes that $T$ and $S$ remain close to $T_{0}$ at the bed, and $C=0.7 \times 1^{-7} \mathrm{~K} /\left(\mathrm{N} \mathrm{m}^{-2}\right)$. Following Kamb (1970) the first-order dependence is on pressure $p$ only with no contribution from deviatoric stress changes.

Figure I shows the overall plane-flow problem, with coordinates $(x, y)$ respectively along and normal to a bed line which is inclined at angle $\alpha$ to the horizontal. $U_{\mathrm{s}}$ is the surface velocity at $y=h$, in the $x$-direction, and the basal-sliding velocity $U_{\mathrm{b}}$ is defined as the leadingorder term of the $x$-velocity in a flow continued onto $y=0$. The bed profile is

$$
y_{\mathrm{b}}=f(x) \text {, }
$$

where $f(x)$ is smooth and extends periodically as $x \rightarrow \pm \infty$. It is assumed that the bed slope is everywhere small, thus

$$
\epsilon=\left|f^{\prime}(x)\right|_{\max } \ll \mathrm{I} .
$$




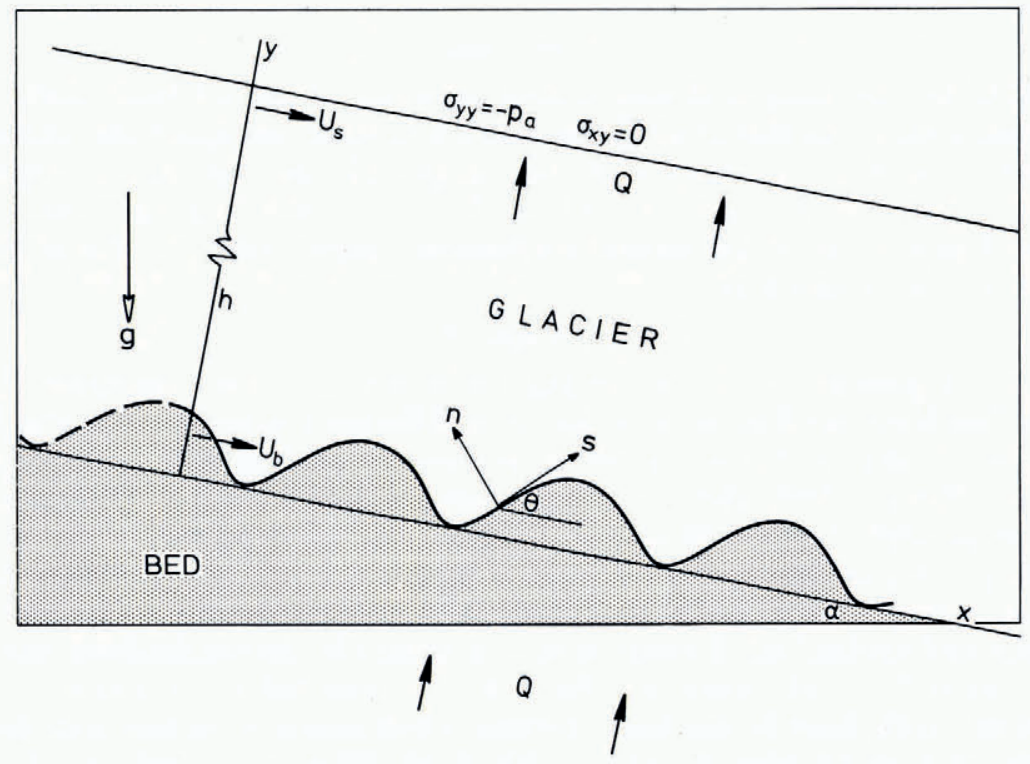

Fig. 1. Glacier flow over a wavy bed.

The bed conditions (Equations ( $\mathrm{I}$ ) or (2)) and Equations (3) and (4) are applied on $y=y_{\mathrm{b}}(x)$. On the upper free surface the stress $\sigma$ satisfies

$$
y=h: \quad \sigma_{y y}=-p_{\mathrm{a}}, \quad \sigma_{x y}=0,
$$

where $p_{\mathrm{a}}$ is atmospheric pressure, and where it is anticipated that the normal velocity $V_{y}$ on $y=h$ is zero to the required order in $\epsilon$. The exponential decay of $V_{y}$ with height demonstrated in the solutions justifies the surface prescription $y \equiv h$ under a very weak restriction on $h$. A geothermal heat flux $Q$ normal to the bed line, with a typical value of $4 \times 10^{-2}$ $\mathrm{J} \mathrm{m}^{-2} \mathrm{~s}^{-1}$ (Paterson, 1969 ) is included, requiring

$$
T \approx-\frac{Q}{k_{\mathrm{i}}} y \text { as } y \rightarrow \infty, \quad S \approx-\frac{Q}{k_{\mathrm{b}}} y \text { as } y \rightarrow-\infty,
$$

in the half-plane solutions determined for $T$ and $S$.

\section{Flow equations}

The construction of velocity and temperature fields, in terms of complex potentials, and the development of boundary-condition expansions in powers of $\epsilon$, have been described by Morland (1976). Equations from this earlier paper are prefixed by the letter "M", only the main steps are repeated here.

A length scale of the bed undulation $\lambda$ is defined by

$$
\lambda=f_{\mathrm{m}} / \epsilon, \quad \text { where } f_{\mathrm{m}}=|f(x)|_{\max },
$$

and dimensionless coordinates $(X, Y)$ are defined by

in which the bed profile becomes

$$
x=\lambda X, \quad y=\lambda Y,
$$

$$
\left.\begin{array}{c}
\Upsilon_{\mathrm{b}}=f(\lambda X) / \lambda=\epsilon F(X) ; \\
|F(X)| \leqslant \mathrm{I}, \quad\left|F^{\prime}(X)\right| \leqslant \mathrm{I} .
\end{array}\right\}
$$


The following velocity, pressure and temperature decompositions are formulated:

$$
\begin{gathered}
\frac{V_{x}}{U_{\mathrm{s}}}=\mathrm{I}-\kappa\left(\mathrm{I}-\frac{\lambda r}{h}\right)^{2}+u, \quad \frac{V_{y}}{U_{\mathrm{s}}}=v, \\
p=p_{0}-\rho g \cos \alpha \lambda r+\frac{2 \mu U_{\mathrm{s}}}{\lambda} P, \quad p_{0}=p_{\mathrm{a}}+\rho g \cos \alpha h, \\
T=T_{0}-\frac{\lambda Q}{k_{\mathrm{i}}} r+\frac{2 \mu U_{\mathrm{s}} C}{\lambda} \tilde{T}, \quad S=T_{0}-\frac{\lambda Q}{k_{\mathrm{b}}} r+\frac{2 \mu U_{\mathrm{s}} C}{\lambda} \tilde{S},
\end{gathered}
$$

where $\mu$ is the ice viscosity and

$$
\kappa=\frac{\rho g \sin \alpha h^{2}}{2 \mu U_{\mathrm{s}}} .
$$

A value for $\mu$ of $3 \times 10^{12} \mathrm{~N} \mathrm{~m}^{-2} \mathrm{~s}$ is used in the calculations. For given values of $\alpha$ and $h$, Equation (15) determines $U_{\mathrm{s}}$ once $\kappa$ is known. The velocities $u$ and $v$ are dimensionless with a scale unit $U_{\mathrm{s}}, P$ is a dimensionless pressure with unit $2 \mu U_{\mathrm{s}} / \lambda$ ( $\boldsymbol{\Sigma}$ will denote a dimensionless stress tensor with the same unit), $\tilde{T}$ and $\tilde{S}$ are dimensionless temperatures with unit $2 \mu U_{\mathrm{s}} C / \lambda$. The free surface conditions of Equation (7) and the flux conditions of Equation (8) are satisfied exactly if

$$
\left.\begin{array}{c}
r=h / \lambda, \quad u=v=P=0 \\
\tilde{T} \rightarrow 0 \quad \text { as } Y \rightarrow \infty, \quad \tilde{S} \rightarrow 0 \quad \text { as } Y \rightarrow-\infty .
\end{array}\right\}
$$

The condition of momentum balance is satisfied for slow viscous flow if

and

$$
\left.\begin{array}{l}
\nabla^{2} P=0, \\
\frac{\partial P}{\partial X}=\frac{1}{2} \nabla^{2} u, \\
\frac{\partial P}{\partial Y}=\frac{1}{2} \nabla^{2} v,
\end{array}\right\}
$$

so that $P, u$ and $v$ are the pressure and velocity fields for viscosity 0.5 in the absence of any body force (Langlois, 1964 ). $\nabla^{2}$ is the two-dimensional Laplacian in $(X, Y)$ coordinates. Steady heat conduction in the ice and bed respectively requires that

$$
\nabla^{2} \tilde{T}=0 \quad \text { and } \quad \nabla^{2} \tilde{S}=0
$$

if we neglect the motion of the ice (Kamb, 1970). Solutions of the biharmonic relations (Equation (17)) and the harmonic relations (Equations (18)) can be expressed in terms of analytic functions of a complex variable $z=X+\mathrm{i} r$ (equations $\left(\mathbf{M}_{43}\right)$ to $\left(\mathbf{M}_{47}\right)$ ). Let the values of $u, v, \tilde{T}$ and $\tilde{S}$ on $r=\mathrm{o}$ (continued analytically where $r=\mathrm{o}$ lies outside the domain) be denoted by

$$
\left.\begin{array}{rl}
u(X, \mathrm{o}) & =U(X), \\
v(X, \mathrm{o}) & =V(X), \\
\tilde{T}(X, \mathrm{o}) & =\Theta(X), \\
\tilde{S}(X, \mathrm{o}) & =\Omega(X),
\end{array}\right\}
$$

and also assume that $U, \mathrm{I}, \Theta$ and $\Omega$ vanish or behave sinusoidally as $X \rightarrow \pm \infty$. Then, assuming that the complex potentials vanish at infinity in a way consistent with Equation (I6), the potentials may be represented as Cauchy integrals of $U, V, \Theta$ and $\Omega$ (equations (M50)$\left.\left(\mathrm{M}_{53}\right)\right)$. 
The boundary values at $r=r_{\mathrm{b}}(X)$, which arise in the bed conditions (Equations (1)-(4)), can be approximated by a truncated Taylor series in $Y$ about $Y=0$. The series appears as a power expansion in $\epsilon$ by virtue of Equation (I I). Evaluation of the various quantities and derivatives on $r=0$ is made from equations ( $\left.\mathbf{M}_{50}\right)-\left(\mathbf{M}_{53}\right)$, these involve Hilbert transforms (Erdélyi, 1954). If $W(t)$ is continuous and vanishes or behaves sinusoidally at infinity, then its Hilbert transform is

$$
H[W](X)=\frac{1}{\pi} \int_{-\infty}^{\infty} \frac{W(t)}{t-X} \mathrm{~d} t,
$$

where $f$ denotes the Cauchy principal value. Also

and

$$
\left.\begin{array}{c}
\frac{d H[W]}{d X}=H\left[W^{\prime}\right] \\
H[H[W]]=-W,
\end{array}\right\}
$$

the latter being the inversion theorem. The useful results when $F(x)$ is a truncated Fourier series are

$$
\left.\begin{array}{rl}
H[\mathrm{I}] & =0, \\
H[\sin k t] & =\cos k X, \\
H[\cos k t] & =-\sin k X ;
\end{array}\right\}
$$

the constant function does not satisfy the inversion theorem.

Now the bed conditions represented by Equations (3) and (4) are given by equations (M65), (M63) and (M62), respectively. Neglecting terms of order $\epsilon^{2}(U, V, \Theta, \Omega)$, these are

$$
\begin{gathered}
-H\left[\Theta^{\prime}+r \Omega^{\prime}\right]+\epsilon\left\{F\left(\Theta^{\prime \prime}-r \Omega^{\prime \prime}\right)+F^{\prime}\left(\Theta^{\prime}-r \Omega^{\prime}\right)\right\}=2 \omega^{2}\left\{V-\epsilon(\mathrm{I}-\kappa) F^{\prime}-\epsilon(F U)^{\prime}\right\}, \\
\Theta+\epsilon F H\left[\Theta^{\prime}\right]=U^{\prime}+H\left[V^{\prime}\right]+\epsilon F\left\{B+H\left[U^{\prime \prime}\right]-V^{\prime \prime}\right\}, \\
\Theta-\Omega+\epsilon F H\left[\Theta^{\prime}+\Omega^{\prime}\right]=\epsilon D F .
\end{gathered}
$$

The argument $X$ is omitted for brevity. A natural length $\lambda_{*}$, and later a length $\lambda_{*}$, occur, these are defined by

$$
\left.\begin{array}{l}
\lambda_{*}=2\left(\frac{\mu k_{\mathrm{i}} C}{L}\right)^{\frac{1}{2}}=0.077 \mathrm{~m}, \\
\lambda_{*}=\left(\frac{\mathrm{I}+r}{2}\right)^{\frac{1}{2}} \lambda_{*}=0.088 \mathrm{~m},
\end{array}\right\}
$$

with previous values, and the ratios

$$
\omega=\lambda / \lambda_{*}, \quad \bar{\omega}=\lambda / \bar{\lambda}_{*},
$$

are introduced for convenience. The constants $B$ and $D$ in Equations (24) and (25) are given by

$$
\left.\begin{array}{l}
B=\frac{\kappa}{\sin \alpha}\left(\cos \alpha+\frac{Q}{\rho g k_{\mathrm{i}} C}\right)\left(\frac{\lambda}{h}\right)^{2}, \\
D=\frac{r-\mathrm{I}}{r} \frac{\kappa}{\sin \alpha} \frac{Q}{\rho g k_{\mathrm{i}} C}\left(\frac{\lambda}{h}\right)^{2} .
\end{array}\right\}
$$


The bed conditions given by Equations (1) and (2) require expansions for the dimensionless tractions $\Sigma_{s}$ and $\Sigma_{n}$, and the dimensionless tangential velocity $V_{s} / U_{\mathrm{s}}$. To the same approximation as Equations (23)-(25), these expansions are:

$$
\begin{array}{r}
\Sigma_{s}=\kappa \frac{\lambda}{h}\left\{\mathrm{I}-\frac{\lambda}{h} \epsilon F-2 \epsilon^{2}\left(F^{\prime}\right)^{2}\right\}+H\left[U^{\prime}\right]-\epsilon\left\{F H\left[V^{\prime \prime}\right]+2\left(F U^{\prime}\right)^{\prime}\right\}, \\
-\Sigma_{n}=\beta \kappa \frac{\lambda}{h}\left\{\mathrm{I}-M \frac{\lambda}{h} \epsilon F\right\}-H\left[V^{\prime}\right]+2 \kappa \frac{\lambda}{h} \epsilon F^{\prime}\left\{\mathrm{I}-\frac{\lambda}{h} \epsilon F\right\}+ \\
+\epsilon\left\{F H\left[U^{\prime \prime}\right]+2 F^{\prime} H\left[U^{\prime}\right]\right\},
\end{array}
$$

where

$$
\begin{gathered}
\frac{\lambda p_{0}}{2 \mu U_{\mathrm{s}}}=\beta \kappa \frac{\lambda}{h}, \quad \beta=\frac{\cot \alpha}{M}, \\
M=\frac{\rho g \cos \alpha h}{p_{\mathrm{a}}+\rho g \cos \alpha h}=O(\mathrm{I}), \\
\frac{V_{s}}{I_{\mathrm{s}}}=\mathrm{I}-\kappa+U+2 \kappa \frac{\lambda}{h} \epsilon F+\epsilon\left\{2 F H\left[U^{\prime}\right]-F^{\prime \prime}+F^{\prime} V^{\prime}\right\} .
\end{gathered}
$$

It is supposed that

$$
\frac{\lambda}{h} \leqslant O(\epsilon)
$$

so that Equation $(16)$ is satisfied to any order in $\epsilon$ with the exponential decay of $u, v$ and $P$ in $r$. Also

$$
\beta=O(\mathbf{I} / \epsilon) \quad \text { if } \alpha=O(\epsilon), \quad \beta=O(\mathbf{1}) \quad \text { if } \alpha=O(\mathbf{I}) .
$$

In order to balance the boundary conditions in powers of $\epsilon$, let

$$
\left.\begin{array}{c}
U=U_{0}+U_{1} \epsilon+U_{2} \epsilon^{2}+\ldots, \\
V=V_{0}+V_{1} \epsilon+V_{2} \epsilon^{2}+\ldots,
\end{array}\right\}
$$

A determination of the coefficients $\gamma_{r}$ gives $\kappa$ in terms of $\lambda / h$ and, in turn, $U_{\mathrm{s}}$ and $U_{\mathrm{b}}$. It is expected that $\kappa \leqslant O(\mathrm{I})$ so $\gamma_{0}=0$, but this will follow from the balance of the boundary conditions.

Finally, if a proportion $j$ of the work done against basal friction is released as heat, then in Equation (3) $V_{n}$ is replaced by $V_{n}+j t_{s} V_{s} / L$. For the Coulomb law (Equation (I)) $t_{s}$ is of order $\rho g h$ (and possibly also for the velocity power law (Equation (2)) when $\alpha$ is of order $\mathbf{I}$ ) and generally $\left(V_{n} / V_{s}\right)$ is of order $\epsilon$, so neglect of the coupling term requires

$$
j h / \epsilon \ll 3 \times 10^{4} \text {. }
$$

This is satisfied for small $j$, or $j$ approximately one, provided $h$ is moderate. In fact, for Equation (2) the condition for no cavitation when $\alpha$ is of order one also requires that $h$ be not too large. When $\alpha$ is of order $\epsilon, t_{s} \leqslant O(\rho g h \alpha)$, and non-coupling only requires $j h \ll 3 \times 10^{4}$.

\section{Coulomb law}

The bed conditions are given by Equations (23) to (25) together with Equation (1) written in the form

$$
\Sigma_{s}=-\nu \Sigma_{n},
$$

where $\Sigma_{s}$ and $\Sigma_{n}$ are given by Equations (29) and (30). First, consider

$$
\alpha=O(\epsilon), \quad \beta=\beta_{1} / \epsilon, \quad \beta_{1}=O(\mathrm{r}),
$$


and suppose $\omega$ is of order I in the series balance. Values of $\omega$ which are smaller or larger may be treated directly, or obtained as limits to the present solution.

The term in $\epsilon^{-1}$ gives immediately from Equation (39)

$$
\gamma_{\mathrm{o}}=\mathrm{o} \text {, }
$$

and the $\epsilon^{0}$ terms give

which imply that

and

$$
\left.\begin{array}{rl}
H\left[U_{0}^{\prime}\right] & =\nu\left(\beta_{1} \gamma_{1}-H\left[V_{0}^{\prime}\right]\right), \\
\gamma_{1} & =0, \\
U_{0} & =-\nu V_{0},
\end{array}\right\}
$$

setting constant terms to zero in order to obtain the required behaviour at infinity. Now the $\epsilon^{0}$ terms of Equations (23) to (25) give

$$
\Theta_{0}=\Omega_{0}=H\left[V_{0}{ }^{\prime}\right]-\nu V_{0}{ }^{\prime}, \quad-(\mathrm{I}+r) H\left[\Theta_{0}{ }^{\prime}\right]=2 \omega^{2} V_{0},
$$

leading to

$$
V_{0}^{\prime \prime}-\bar{\omega}^{2} V_{0}+\nu H\left[V_{0}^{\prime \prime}\right]=0 .
$$

$\Lambda$ scarch for a periodic solution without constant term,

$$
V_{0}=\sum_{n=1}^{\infty}\left(a_{n} \cos \xi_{n} X+b_{n} \sin \xi_{n} X\right), \quad \xi_{n}=2 \pi n / l,
$$

and the use of the results of Equation (22) shows that both $a_{n}$ and $b_{n}$ are zero, so

$$
\left.\begin{array}{l}
U_{0}=0 \\
V_{0}=0 \\
\Theta_{0}=0 \\
\Omega_{0}=0 .
\end{array}\right\}
$$

Similarly, the $\epsilon$ terms of Equations (39) show that

and

$$
\left.\begin{array}{l}
\gamma_{2}=0 \\
U_{1}=-\nu V_{1},
\end{array}\right\}
$$

and Equations (24) and (25) show that

$$
\Omega_{1}=\Theta_{1}-D F, \quad \Theta_{1}=B F+H\left[V_{1}^{\prime}\right]-\nu V_{1}^{\prime} .
$$

Using these results in the $\epsilon$ balance of Equation (23) gives

$$
V_{1}^{\prime \prime}-\bar{\omega}^{2} V_{1}+\nu H\left[V_{1}^{\prime \prime}\right]=-\bar{\omega}^{2}(\mathrm{I}-\kappa)\left\{F^{\prime}-A H\left[F^{\prime}\right]\right\},
$$

where

$$
B-\frac{r}{\mathrm{I}+r} D=A(\mathrm{I}-\kappa) \bar{\omega}^{2} .
$$

It was shown in Morland ( 1976 ) that $A$ has a maximum value of 0.05 for extreme values of the glacier parameters, so contributions to the geothermal heat flux which arise solely from this coefficient are small. The bounded complementary solution of Equation (49) is zero, analogous to Equation (44). The determination of a particular periodic integral needs $F$ to be specified. As an illustration of this consider a sinusoidal bed whose shape is described by the equation

$$
F(X)=\sin X
$$


The solution of Equation (49) is now

$$
\begin{gathered}
V_{\mathrm{I}}=a \cos X+b \sin X \\
{\left[\left(\mathrm{I}+\bar{\omega}^{2}\right)^{2}+\nu^{2}\right]\left(\begin{array}{l}
a \\
b
\end{array}\right)=(\mathrm{I}-\kappa) \bar{\omega}^{2}\left(\begin{array}{c}
\mathrm{I}+\bar{\omega}^{2}-\nu A \\
A\left(\mathrm{I}+\bar{\omega}^{2}\right)+\nu
\end{array}\right) .}
\end{gathered}
$$

As $\nu$ tends to zero, $U_{1}$ tends also to zero, and

$$
a \rightarrow \frac{(\mathrm{I}-\kappa) \bar{\omega}^{2}}{\mathrm{I}+\bar{\omega}^{2}}, \quad b \rightarrow \frac{A(\mathrm{I}-\kappa) \bar{\omega}^{2}}{\mathrm{I}+\bar{\omega}^{2}} ;
$$

thus we recover the solution for perfect slip (Morland, 1976).

The leading velocity terms $U_{\mathrm{I}}$ and $V_{\mathrm{I}}$ are now determined but, in contrast with the perfect slip solution, $\gamma_{2}=0$ and so $\kappa, U_{\mathrm{s}}$ and $U_{\mathrm{b}}$ are still unknown. From the $\epsilon^{2}$ terms of Equation (39)

$$
H\left[U_{2}^{\prime}\right]-F H\left[V_{1}^{\prime \prime}\right]-2\left(F U_{1}^{\prime}\right)^{\prime}=\nu\left\{\beta_{1} \gamma_{3}-H\left[V_{2}^{\prime}\right]+F H\left[U_{1}^{\prime \prime}\right]+2 F^{\prime} H\left[U_{1}^{\prime}\right]\right\} .
$$

Thus, the second-order velocity coefficient $U_{2}$ is given by the balance of periodic terms whereas $\beta_{1} \gamma_{3}$ is equal to the constant term of

$$
-\left\{F H\left[U_{\mathrm{I}}{ }^{\prime \prime}\right]+2 F^{\prime} H\left[U_{1}^{\prime}\right]+\nu^{-1} F H\left[V_{1}^{\prime \prime}\right]\right\} .
$$

For the profile represented by Equation ( $5 \mathrm{I}$ )

$$
\beta_{1} \gamma_{3}=-\frac{a}{2 \nu}\left(\mathrm{I}+v^{2}\right)<0 \quad \text { for } \nu A<\mathrm{I}+\bar{\omega}^{2},
$$

which, since $\kappa$ and $\beta_{1}$ are positive, implies that $U_{\mathrm{s}}$ is less than zero. This contradictory result stems from the application of Equation (39) to the regions of negative pressure $\left(\Sigma_{n}>0\right)$ given in this solution, when the friction $\left(\Sigma_{s}<0\right)$ is directed up-glacier. From Equation (3o) the leading normal pressure term is

$$
\begin{aligned}
-\Sigma_{n} & \sim-\epsilon H\left[V_{1}^{\prime}\right] \\
& =\epsilon(a \cos X+b \sin X)
\end{aligned}
$$

which oscillates equally between positive and negative values. Thus there is no balance without cavitation for Equations (39) and (40).

Now, $\alpha$ is of order one as are both $\beta$ and $\beta_{0}$. If we assume that $\nu \beta_{0}$ is not equal to one, then the $\epsilon^{0}$ terms of Equation (39) give

and

$$
\left.\begin{array}{l}
\gamma_{0}=0, \\
U_{0}=-\nu V_{0},
\end{array}\right\}
$$

and so Equations (23) to (25) lead to Equations $(43)$ to $(46)$ again. Similarly, the $\epsilon$ terms give

$$
\left.\begin{array}{l}
\gamma_{\mathrm{I}}=0, \\
U_{\mathrm{I}}=-\nu V_{1},
\end{array}\right\}
$$

and also Equations $\left(4^{8}\right)$ to $(54)$, while the $\epsilon^{2}$ terms of Equation (39) give Equation ( 56 ) for a left-hand side of $\gamma_{2}\left(\beta_{0}-\nu^{-1}\right)$. Thus

$$
\gamma_{2}=\frac{a\left(\mathrm{I}+\nu^{2}\right)}{2\left(\mathrm{I}-\nu \beta_{0}\right)}
$$

which tends to $(\mathrm{I}-\kappa) \bar{\omega}^{2} /\left(2\left(\mathrm{I}+\bar{\omega}^{2}\right)\right)$ as $\nu$ tends to zero; we recover the perfect slip solution in this case also. Provided $\nu$ is less than $\mathrm{I} / \beta$ then we are able to predict a positive surface velocity $U_{\mathrm{s}}$. But, again, Equation $\left(5^{8}\right)$ determines the leading normal pressure term, showing 
that there is no balance without cavitation. The case where $\nu \beta_{0}$ is equal to one allows a balance only if $U_{\mathrm{s}}$ is zero.

In conclusion, the solutions constructed for the Coulomb law, assuming no cavitation, are invalid for all ranges of bed-line inclination $\alpha$.

\section{Velocity power LaW}

The law represented by Equation (2) can be rewritten as

$$
\Sigma_{s}=E \frac{\lambda}{2 \mu} U_{\mathrm{s}}^{(1 / m)-1}\left(\frac{V_{s}}{U_{\mathrm{s}}}\right)^{1 / m},
$$

but we lack data for the physical constant $E$. However, if we suppose that $t_{s}$ is less than or equal to $\rho g h \sin \alpha$ (a condition compatible with the gravity driving force) then

$$
\begin{aligned}
\Sigma_{s} & \leqslant O(\kappa \lambda / h) \\
& \leqslant O(\lambda / h),
\end{aligned}
$$

since $\kappa$ is of the order of one for $U_{b}$ greater than zero. This is satisfied by the equation

$$
\Sigma_{s}=e\left(\frac{\lambda}{h}\right) \kappa^{1-(1 / m)}\left(\frac{V_{s}}{U_{\mathrm{s}}}\right)^{1 / m}
$$

where $e$ is less than or equal to the order of one provided that $\kappa$ is of order one. If any solution with $e$ of order one predicts a smaller $\kappa$, and hence a $V_{s}$ of the order of $U_{\mathrm{b}}$ and $U_{\mathrm{s}}$, then larger values of $t_{s}$ occur, presumably with compensating bed tensions as with the Coulomb law, so that cavitation occurs. However, the form of Equation $\left(6_{3}\right)$ includes all possible valid situations. By construction, the equation

$$
e=E /\left\{(2 \mu)^{1 / m}(\rho g \sin \alpha)^{1-(1 / m)} h^{1-(2 / m)}\right\},
$$

is independent of the solution variable $U_{\mathbf{s}}$, but depends explicitly on $\alpha$ and on $h$ if $m$ is not equal to 2. The perfect slip law $\Sigma_{s}=0$ is given by the limit as $e$ tends to zero.

Now $V_{s}$ is of order $U_{\mathrm{b}}$, and if

$$
\begin{aligned}
U_{\mathrm{b}} / U_{\mathrm{s}} & =\mathrm{I}-\kappa+U_{\mathrm{o}} \\
& \approx \mathrm{o},
\end{aligned}
$$

then Equation (62) approaches the perfect slip law. These conditions do not, in general, follow Morland (1976), so we assume that

$$
\frac{U_{\mathrm{b}}}{U_{\mathrm{s}}}=\mathrm{I}+\kappa+U_{\mathrm{o}}=O(\mathrm{I}),
$$

and hence from Equation (33)

$$
\left(\frac{V_{s}}{U_{\mathrm{s}}}\right)^{1 / m}=\left(\mathbf{I}-\kappa+U_{\mathrm{o}}\right)^{1 / m}+O(\epsilon) .
$$

With the restriction of Equation (34) the $\epsilon^{0}$ terms of Equation (63) give

$$
\gamma_{0}=0, \quad U_{0}=0 \text {, }
$$

and then, the $\epsilon^{0}$ terms of Equations (23) to (25) are identical with the perfect slip balance implying that

$$
\left.\begin{array}{l}
V_{0}=0, \\
\Theta_{0}=0, \\
\Omega_{0}=0 .
\end{array}\right\}
$$

Next, the $\epsilon$ terms of Equation (63) give

$$
U_{1}=0: \quad \gamma_{1} \kappa\left\{1-e\left(\frac{1-\kappa}{\kappa}\right)^{1 / m}\right\}=0 .
$$


One solution to these equations is

$$
\gamma_{1} \neq 0, \quad\left(\frac{\kappa}{1-\kappa}\right)^{1, m}=e,
$$

thus determining $\kappa, U_{\mathrm{b}}$, and $U_{\mathrm{s}}$ independent of $F(X)$. Again, the $\epsilon$ balance of Equations (23) to $(25)$ is identical with the perfect slip solution, so

$$
V_{1}^{\prime \prime}-\bar{\omega}^{2} V_{1}=-(\mathbf{1}-\kappa) \bar{\omega}^{2}\left\{F-A H\left[F^{\prime} 1\right\},\right.
$$

and, for the sinusoidal bed (Equation $\left(5^{I}\right)$ ).

$$
\Gamma_{1}=\frac{(\mathbf{I}-\boldsymbol{\kappa}) \bar{\omega}^{2}}{\mathbf{I}+\bar{\omega}^{2}}(\cos X+A \sin X) .
$$

In the limit as $e$ tends to zero, Equation (69) implies that $\gamma_{1}=0$ as in the perfect slip solution.

The alternative solution of Equation (69) is simply

$$
\gamma_{1}=0 \text {, }
$$

and the perfect-slip results (Equations $(71)$ and (72)) again follow. Now, the $\epsilon^{2}$ balance in Equation $\left(6_{3}\right)$ requires that

$$
\gamma_{2}+H\left[U_{2}^{\prime}\right]-F H\left[I_{1}^{\prime}{ }^{\prime \prime}\right]=e \gamma_{2}\left(\frac{1-\kappa}{\kappa}\right)^{1 / m} .
$$

The product $F H\left[V_{1}^{\prime \prime}\right]$ is in general the sum of a constant $\Gamma$ and a periodic term $I I^{*}$ ), as in the perfect slip solution, so

$$
\begin{aligned}
U_{2}^{\prime} & =-H\left[W^{\prime}\right], \\
\kappa\left\{\mathrm{I}-e\left(\frac{\mathrm{I}-\kappa}{\kappa}\right)^{1 / m}\right\} & =\frac{\Gamma h \epsilon^{2}}{\lambda},
\end{aligned}
$$

where a non-zero $\Gamma$ implies that $\gamma_{2}$ is not equal to zero. As

$$
\begin{aligned}
\gamma_{2} & \rightarrow O(\mathrm{I} / \epsilon), \\
\frac{h \epsilon^{2}}{\kappa \lambda} & \rightarrow O(\epsilon),
\end{aligned}
$$

(which is equivalent to $\gamma_{1}$ being non-zero), Equation (75) approaches the result (Equation (70)). Thus, the first solution is given by taking small values for $h \epsilon^{2}$ in Equation ( $75^{\mathrm{b}}$ ). For the sinusoidal bed (by equation (M88))

$$
F H\left[V_{1}^{\prime \prime}\right]=\frac{(\mathbf{I}-\kappa) \bar{\omega}^{2}}{2\left(\mathbf{I}+\bar{\omega}^{2}\right)}\{\mathrm{I}-\cos 2 X-A \sin 2 X\},
$$

and $U_{2}$ and $V_{2}$ are given by the perfect slip solutions (equations (M9o) and (M94)). Thus the velocity perturbation is changed only by the scale factor $U_{\mathbf{s}}$, which changes with $\kappa$ (Equation (8)). Now Equation $(75 \mathrm{~b})$ becomes

$$
\frac{\kappa}{\mathrm{I}-\kappa}-e\left(\frac{\kappa}{\mathrm{I}-\kappa}\right)^{1-(1 / m)}-\frac{h \epsilon^{2} \bar{\omega}}{2 \lambda_{*}\left(\mathrm{I}+\bar{\omega}^{2}\right)}=0 .
$$

When $e=0$, Equation (77) reduces to the perfect slip result (equation (M89)).

The basal-sliding velocity is given by

$$
U_{\mathrm{b}}=\frac{\mathrm{I}-\kappa}{\kappa} \frac{\rho g \sin \alpha h^{2}}{2 \mu}
$$

and, for fixed values of $h$ and $\bar{\omega}$, as $e$ increases $\kappa /(\mathbf{I}-\kappa)$ increases and so $U_{\mathrm{b}}$ decreases. As expected, friction decreases the sliding velocity. Calculations have been made for $m=2$. Figures 2 and 3 show the variation of $l_{b}$ with $\bar{\omega}$ for values for $h \epsilon^{2}$ of $0.1,0.4,1$, and 4 , for $e=0.5$ (Fig. 2) and $e=1$ (Fig. 3), compared with $L_{\mathrm{b}}$ of the perfect-slip solution $(e=0)$. 
In the perfect-slip case the ratio $U_{\mathrm{b}} \epsilon^{2} / h$ is independent of $h \epsilon^{2}$. For $\epsilon \approx 0.1$, this range of $h \epsilon^{2}$ covers values of $h$ running from $10-400 \mathrm{~m}$. If $e, \epsilon$ and $\bar{\omega}$ are fixed, we see that $U_{\mathrm{b}}$ decreases as $h$ decreases. Also, for fixed $e$, the variation of $U_{\mathrm{b}}$ with $\bar{\omega}$ (the length scale of the undulation) decreases as $h$ decreases, and, in particular, $U_{\mathbf{b}}$ is very insensitive to changes in $\bar{\omega}$ provided $h$ is small. (As the graph ordinates are proportional to $U_{\mathrm{b}} / h$ (Figs 2 and 3 ), so these effects are more significant than the Figures appear to suggest. Figure 4 shows the variation of the ratio $U_{\mathrm{b}} / U_{\mathrm{s}}$ with $\bar{\omega}$ for the values of $h \epsilon^{2}$ used in the previous Figures. This ratio decreases with increase of $e$ for each value of $h \epsilon^{2}$ and $\bar{\omega}$, including the case where $e=0$ (figure 3 , Morland (1976)). At fixed $e, U_{\mathrm{b}} / U_{\mathrm{s}}$ becomes less sensitive to a change in $\bar{\omega}$ as $h \epsilon^{2}$ decreases. At both fixed $e$ and $\bar{\omega}$, the ratio increases as $h \epsilon^{2}$ decreases.

Finally, the relation for normal bed pressure (Equation (30)) has leading terms (recall Equation (40))

$$
\left.\begin{array}{ll}
\alpha=O(\epsilon): & -\Sigma_{n} \sim \beta_{1} \gamma_{1}+\epsilon\left(\beta_{1} \gamma_{2}-H\left[V_{1}^{\prime}\right]\right), \\
\alpha=O(\mathbf{I}): & -\Sigma_{n} \sim \epsilon\left(\beta_{0} \gamma_{1}-H\left[V_{1}^{\prime}\right]\right) .
\end{array}\right\}
$$

Now if $\lambda / h$ is of order $\epsilon$, Equation (77) reduces to Equation ( 70$)$ with $\gamma_{1} \neq 0, \kappa=O(\mathrm{I})$, and, for such relatively thin glaciers, Equation (79) shows that there is no cavitation if $\alpha$ is of order $\epsilon$, or if $\alpha$ is of order one and

$$
\beta_{0} \gamma_{1} \geqslant\left(H\left[V_{1}^{\prime}\right]\right)_{\max }
$$

For the sinusoidal bed the latter condition becomes

$$
\alpha=O(\mathrm{I}): \quad \tan \alpha \leqslant \frac{\lambda\left(\mathrm{I}+\bar{\omega}^{2}\right) e^{m}}{h \epsilon \bar{\omega}^{2}}\left(\mathrm{I}+\frac{p_{\mathrm{a}}}{\rho g h \cos \alpha}\right) .
$$

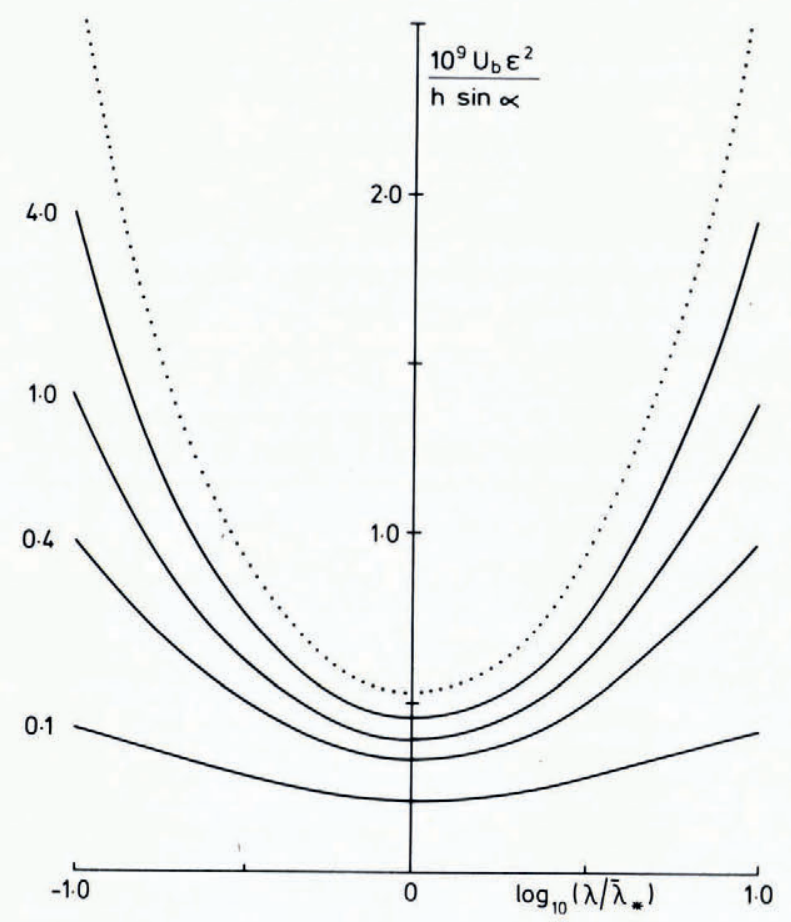

Fig. 2. Variation of basal sliding velocity $U_{\mathrm{b}}$ with undulation length $\lambda$ (SI-units) for $e=0.5$. The perfect-slip solution $(e=0)$ is shown by the dotted line. 


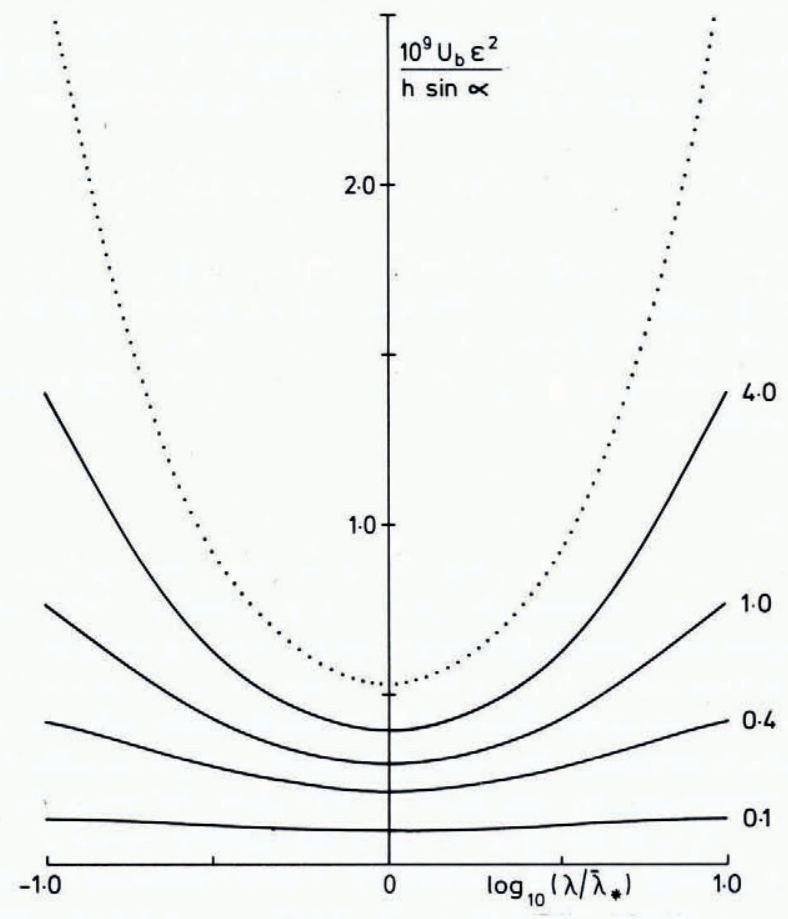

Fig. 3. Variation of basal sliding velocity $U_{\mathrm{b}}$ with undulation length $\lambda$ (SI-units) for $e=1.0$. The perfect-slip solution $(e=0)$ is shown by the dotted line.

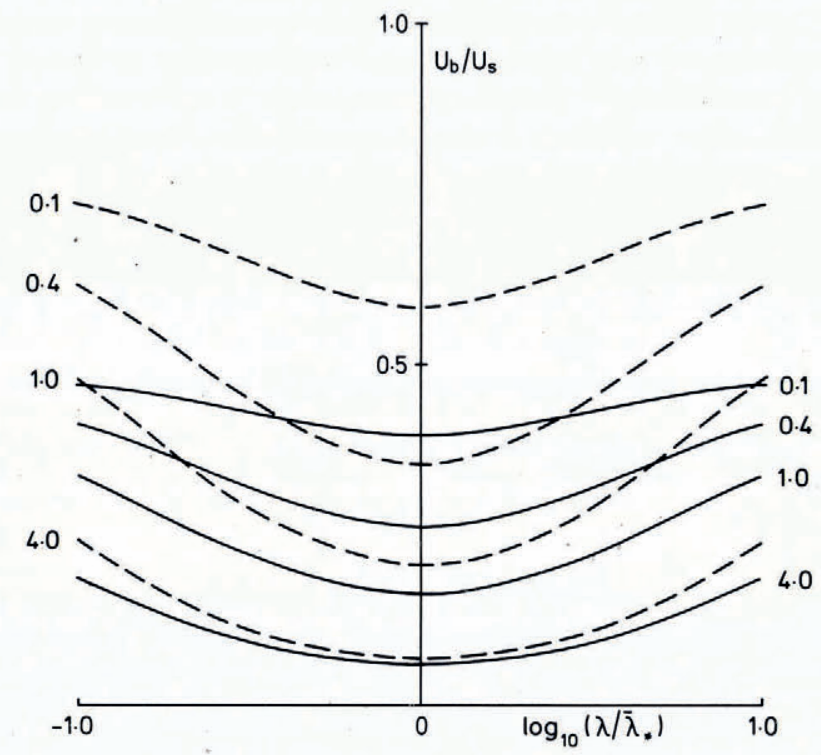

Fig. 4. Variation of the ratio of basal-sliding velocity to surface velocity with undulation length $\lambda$ for different values of h $\epsilon^{2}$ (SIunits). These values are shown against the curves. The dashed lines are for $e=0.5$, the full lines are for $e=I .0$. 
For $\lambda / h$ of order $\epsilon^{2}, \gamma_{1}$ zero and $\gamma_{2}$ non-zero, Equation (79) shows that $\Sigma_{n}$ oscillates about zero to the order of $\epsilon$ when $\alpha$ is of the order of one, so cavitation always occurs then. But for $\alpha$ of the order of $\epsilon$, cavitation does not occur if $\beta_{1} \gamma_{2}$ is greater than or equal to $\left(H\left[V_{1}^{\prime}\right]\right)_{\max }$. For the sinusoidal bed. neglecting the small coefficient $A$, the condition becomes

$$
\alpha=O(\epsilon): \quad \tan \alpha \leqslant \frac{\epsilon \lambda\left(\mathrm{I}+\bar{\omega}^{2}\right)}{h \epsilon^{2} \bar{\omega}^{2}}\left(\mathrm{I}+\frac{p_{\mathrm{a}}}{\rho g h \cos \alpha}\right) \frac{\kappa}{\mathrm{I}-\kappa} .
$$

As with the perfect-slip result of Morland (1976) (equation (M IO2)), there is a critical limit $\alpha_{c}$, of the order $\epsilon$ which increased with the friction coefficient $e$ through the factor $\kappa /(1-\kappa)$.

Thus, the law represented by Equation (2) allows non-cavitation solutions for "thin glaciers" for all $\alpha$ less than or equal to $\alpha_{\mathrm{c}}$ (of order one), and for "thick glaciers" for $\alpha$ less than or equal to $\alpha_{c}$ (of order $\epsilon$ ).

\section{Concluding remarks}

The flow solutions which have been established for both friction laws exhibit features which differ from each other and from the perfect-slip solution. With the Coulomb law (Equation (I)), the normal bed traction becomes a tensile stress over finite sections of the profile however small the inclination $\alpha$; this implies the onset of cavitation and the failure of the solution which assumes contact everywhere. In the perfect-slip solution the bed pressure remains positive everywhere provided that $\alpha$ is less than or equal to $\alpha_{c}$ where $\alpha_{c}$ is of the order of $\epsilon$. Since the mean tangential traction must be less than the mean down-plane gravity force, and by Equation ( $\mathrm{I}) t_{s}$ is of the same order as the normal pressure $-t_{n}$ in the mathematicai solution, regions of large normal pressure are counterbalanced by regions of negative pressure accompanied by negative values of $t_{s}$ (the traction driving the glacier). Thus, the Coulomb law is possible only if a significant amount of cavitation takes place. In contrast, the power-velocity law (Equation (2)) gives a bed pressure which is everywhere positive if $\alpha$ is less than or equal to $\alpha_{c}$ (of order one), provided the glacier depth $h$ is not too large, and if $\alpha$ is less than or equal to $\alpha_{\mathbf{k}}\left(\alpha_{\mathbf{c}}\right.$ of order $\left.\epsilon\right)$ for deep glaciers. Furthermore, the predicted basal-sliding velocity for a sinusoidal bed is smaller and varies much less with the length scale of the undulation than it does in the perfect-slip solution, both the magnitude and variation decreasing as $h$ decreases. These broad features of the different friction laws may be helpful in the construction of friction models from empirical data.

\section{ACKNOWI.LGMENT}

This investigation was pursued in connection with a Natural Environment Research Council Grant GR 3/268o "Flow of glaciers over deformable materials" held jointly with 1)r G. S. Boulton in the School of Environmental Sciences, University of East Anglia.

MS. received 22 .January 1.976 and in revised form I March 1976

\section{REFERENCES}

Boulton, G. S. 1974. Processes and patterns of glacial erosion. (In Cioates, D. R., ed. Glacial geomorphology. Binghamton, State University of New York, p. 41-87. (Publications in Geomorphology.))

Boulton, G. S. 1975. Processes and patterns of subglacial sedimentation: a theoretical approach. (In Wright, A. E., and Moseley, F., ed. Ice ages: ancient and modern. Liverpool. Seel House Press, p. 7-42.)

Erdélyi, A., ed. 1954. Tables of integral transforms. Vol. 2. Based, in part, on notes left by Harry Bateman. New York, etc., McGraw-Hill Book Co., Inc.

Kamb, W. B. 1970. Sliding motion of glaciers: theory and observation. Reviews of Geophysics and Space Physics, Vol. 8, No. 4, p. $673-728$. 
Langlois, W. E. 1964. Slow viscous flow. New York, Macmillan.

Morland, L. W. 1976. Glacier sliding down an inclined wavy bed. Journal of Glaciology, Vol. i 7, No. 77, p. 447-62.

Nye, J. F. 1959. The motion of ice sheets and glaciers. Journal of Glaciology, Vol. 3, No. 26, p. $493-507$.

Nye, J. F. I 969 . A calculation on the sliding of ice over a wavy surface using a Newtonian viscous approximation. Proceedings of the Royal Society of London, Ser. A, Vol. 31 1, No. 1506 , p. 445-67.

Nye, J. F. 1970. Glacier sliding without cavitation in a linear viscous approximation. Proceedings of the Royal Society of London, Ser. A, Vol. 315, No. 1522, p. 381-403.

Paterson, W. S. B. 1969 . The physics of glaciers. Oxford, Pergamon Press. (The Commonwealth and International Library. Geophysics Division.)

Weertman, J. 1957. On the sliding of glaciers. Fournal of Glaciology, Vol. 3, No. 21, p. 33-38.

Weertman, J. I 964 . The theory of glacier sliding. Journal of Glaciology, Vol. 5, No. 39, p. $287-303$. 